\title{
RAPD assisted selection of black gram (Vigna mungo L. Hepper) towards the development of multiple disease resistant germplasm
}

\author{
B. Vishalakshi ${ }^{1}$ B. Umakanth ${ }^{1}$ - Anirudh P. Shanbhag ${ }^{2} \cdot$ Arindam Ghatak $^{4}$ \\ Nitish Sathyanarayanan ${ }^{5}$ M. S. Madhav ${ }^{1}$ G. Gopala Krishna ${ }^{3} \cdot$ Hari Yadla $^{6}$
}

Received: 13 October 2016/Accepted: 2 December 2016/Published online: 7 April 2017

(c) The Author(s) 2017. This article is an open access publication

\begin{abstract}
Black gram (Vigna mungo L. Hepper), is an extensively studied food crop which is affected by many abiotic and biotic factors, especially diseases. The yield potential of Black gram is shallow due to lack of genetic variability and biotic stress susceptibility. Core biotic stress factors include mung bean yellow mosaic virus (MYMV), urdbean leaf crinkle virus (UCLV), wilt (Fusarium oxysporum) and powdery mildew (Erysiphe polygoni DC). Although many studies determine resistant varieties to a particular disease, however, it is often complimented by low yield and susceptibility to other diseases. Hence, this study focuses on investigating the genetic relationships among three varieties and nine accessions of black gram having disease resistance to previously described diseases and susceptibility using random amplified polymorphic deoxyribonucleic acid (RAPD) markers. A total of 33 RAPD primers were used for diversity analysis and yielded
\end{abstract}

B. Vishalakshi and B. Umakanth have contributed to the work equally.

Anirudh P. Shanbhag

anirudh.skylark@gmail.com

1 Biotechnology Section, Crop Improvement Division, Indian Institute of Rice Research (ICAR-IIRR), Hyderabad, India

2 Nuclear Agriculture and Biotechnology Division, Bhabha Atomic Research Centre (BARC), Mumbai, India

3 Agri Biotech Foundation, Rajendra Nagar, Hyderabad, India

4 Biomoneta Research Private Limited, Centre for Cellular and Molecular Platforms, NCBS, (TIFR), Bengaluru, India

5 National Center for Biological Sciences (NCBS), TIFR, Bengaluru, India

6 Regional Research Station (RARS-PJTSAU), Warangal, India
206 fragments. Number of amplified fragments ranged from two (OPN-1) to 13 (OPF-1). The highest similarity coefficient was observed between IC-145202 and IC164118 (0.921), while lowest similarity was between PU31 and IC-145202 (0.572). The genetic diversity obtained in this study along with disease analysis suggests PU31as a useful variety for the development of markers linked to MYMV, UCLV, wilt and powdery mildew resistance by marker-assisted back cross breeding and facilitates the production of crosses with multiple disease resistance.

Keywords Mung bean yellow mosaic virus (MYMV) . Urdbean leaf crinkle virus (UCLV) · Powdery mildew . Wilt · Vigna mungo L. Hepper · Rapid amplification of polymorphic DNA (RAPD)

\section{Introduction}

Vigna mungo L. Hepper (Black gram) is an important source of protein for both humans and cattle. It is grown in the Indian subcontinent as well as in Southeast Asia particularly in Thailand, Australia, and other Asian and South Pacific countries. There is a great need for cultivating richer protein sources for cattle feed and human consumption which has lead to great interest in studying the diversity and pathology in black gram (Wani et al. 2013). It is also one of the central crop resources in Indian cuisine and occupies about 3.15 mha. On an average, the crop yields up to $275 \mathrm{~kg} / \mathrm{ha}$, despite the estimated yield potential to be about $844 \mathrm{~kg} / \mathrm{ha}$ (Amanullah and Hatam 2000).

Studies have been done to delineate the genetic diversity of various pulses including black gram which succeeded in producing high yielding varieties in various regions across Asia. However, high genetic consistency and the absence 
of suitable ideotypes reinforce with deficient harvest and disease susceptibility has caused major constraints in achieving a higher yield (Vyas et al. 2016). Among various biotic factors affecting black gram yield, the main diseases which devastate the crops are mung bean yellow mosaic virus (MYMV), urdbean leaf crinkle virus (UCLV), powdery mildew (PM) and wilt (Fusarium oxysporum).

MYMV, is a whitefly (Bemisia tabaci) transmitted Gemini virus, which hampers resistant black gram breeding due to lack of uniform screening procedures and in numerous cases resistance is governed by recessive genes (Haq et al. 2010). In such circumstances, indirect selection employing molecular markers linked to resistance genes should be an effective approach as they enable markerassisted selection (MAS) to overcome the inaccuracies in the field evaluation (Xu et al. 2012). Few attempts were made to search molecular markers linked to MYMV resistance in black gram by utilizing resistant sources like TU 94-2 and PU 19 through RAPD and ISSR analysis (Souframanien and Gopalakrishna 2004). UCLV is another virus which is ubiquitous in all commercially viable Vigna genus including $V$. mungo, and affects the crop in all stages especially in early stage which devastates total seed yield. In time, leaves become leathery and crinkled and lose the ability to perform normal physiological functions (Gautam et al. 2016).

Powdery mildew (PM) caused by Erysiphe polygoni DC and wilt (Fusarium oxysporum) are two diseases caused by fungi which affect black gram in high humid conditions and are easily transmitted through sporulation. They affect all the parts of the plants, however, leaves are affected initially and the morphology of the plant begins to change as the diseases suggest (Jayasekhar and Ebenezar 2016). Diversity among powdery mildew resistance was estimated against eight black gram ( $V$. mungo) varieties from various geographic locations of Uttar Pradesh and Andhra Pradesh (India) applying forty decamer primers and generated a total of 249 RAPD fragments, of which 224 were polymorphic (Datta et al. 2012).

Previously, genetic diversity analysis among 20 black gram varieties was done by employing RAPD and ISSR markers indicating homology between all the 20 black gram varieties. RAPD markers are very useful due to their simplicity, low cost and high throughput capabilities (Kumari and Thakur 2014). In fact, RAPD technique has been applied to assess molecular polymorphism in mung bean (Datta et al. 2012), chickpea (Singh et al. 2014), pea (Handerson et al. 2014) and pigeon pea (Yadav et al. 2014). Studies among the 20 black gram varieties showed that WBU-108 and RBU-38 were highly divergent, whereas LBG-648 and LBG-623 were genetically similar (Karuppanapandian et al. 2010). Genetic diversity analysis was performed on existing cultivars, to determine whether a lack of genetic variability might be a constraining factor to improvement (Sivaprakash et al. 2004). Host-plant resistance is considered as the most economical and eco-friendly strategy for achieving disease resistance and yield stability.

Current study focuses on predicting crosses between high yielding varieties and accessions which can incorporate resistance to the mentioned diseases. Not only have we chosen the varieties based on varying disease resistance but also taken into account the economic viability of these crops. We carried out genetic diversity analysis among different disease resistant and susceptible varieties utilizing 38 primers. Here is an emerging need to identify nucleic acid markers linked to disease resistance especially in staple crops such as black gram for preventing food deficit in a burgeoning population. The marker can be converted to sequence characterized amplified region (SCAR) to identify the locus of interest by amplification with a specific primer pair it could facilitate marker-assisted selection for rapid evaluation.

\section{Materials and methods}

\section{Plant materials}

Fifteen black gram varieties with varying disease resistance and susceptibility was obtained from Regional Agriculture Research Station, Guntur, India and National Bureau of Plant Genetic Resources, India (Table 1) which are

Table 1 Black gram genotypes resistant and susceptible to various diseases (Srivastava et al. and Obiah et al.)

\begin{tabular}{lll}
\hline Disease & Resistant strains & Susceptible strains \\
\hline Mung bean yellow mosaic virus (MYMV) & PU 1075, PU 31, PU 205 & LBG 623, LBG 645, LBG 685, IC \\
& & 110790, IC 145202, IC 1575, IC \\
& & 164118, IC 20880, IC 59718, IC 61106, \\
& IC 61603, IC 73306 \\
Powdery mildew (PM) & IC 59718, IC 61106, PU 31 & LBG 685 \\
Urdbean leaf crinkle virus (UCLV) & IC 73306 & LBG 645, LBG 685 \\
Wilt (Fusarium oxysporum) & LBG 623, LBG 645, LBG 685 & IC 164118, IC 20880, IC 59718, \\
\hline
\end{tabular}


distributed across northern (sub-tropical conditions) and southern parts of Indian subcontinent (tropical conditions).

\section{Quantity and quality of genomic DNA}

Genomic DNA from the obtained genotypes was isolated using a modified protocol prescribed by Saghai-Maroof et al. (1984). Final concentration of $30 \mathrm{ng} / \mu \mathrm{l}$ of genomic DNA (initial concentration $\sim 100 \mathrm{ng} / \mu \mathrm{l}$ ) was used for PCR (Thermo scientific). Initial denaturation conditions were $94{ }^{\circ} \mathrm{C}$ for $4 \mathrm{~min}$, further continued for $1 \mathrm{~min}$, annealing was at $33{ }^{\circ} \mathrm{C}$ and elongation was done at $72{ }^{\circ} \mathrm{C}$ for $1 \mathrm{~min}$. Final elongation conditions were held for $10 \mathrm{~min}$ at $72{ }^{\circ} \mathrm{C}$. PCR amplified products were subjected to electrophoresis on $1 \%$ agarose gel in 1XTBE buffer. Gel documentation was done using Alpha imager system.

Initially, 40 RAPD primers were tested on a subset of six black gram varieties and nine accessions. These primers were synthesized by Sigma-Aldrich and the sequences were used in previous studies on disease resistance in black gram (Basak et al. 2004; Vyas et al. 2016). Of the 40, only 33 RAPD primers produced clear and reproducible banding patterns. A total of 206 alleles were generated for the 33 selected RAPD primers and this allelic data was converted into binary data for identity matrix based on their presence or absence of alleles in terms of scores 1 and 0 , respectively.

\section{Data analysis}

Allele number was given and scored according to its presence or absence, based on difference in molecular weight. Only the clear and unambiguous bands were scored. Markers (33 RAPD primers) were scored for the presence (1) and absence (0) of the corresponding band among the genotypes. Consequently, a data matrix comprising ' 1 ' and ' 0 ' was formed and subjected to further analysis.

Further processing of data was done by carrying out sequential agglomerative hierarchial non-overlapping clustering (SAHN), on squared Euclidean distance matrix. Similarity matrix was done using Jaccard's coefficient (Table 2) in which similarity matrices were utilized to construct the UPGMA (unweighted pair group method with arithmetic average) dendrogram. Data analysis was done using NTSYs PC (Numerical Taxonomy System, version 2.02).

\section{Results and discussion}

Unraveling genetic diversity is quintessential to plant breeding, as the development of new varieties depends on the existing diversity of parent genotypes. This study
Table 2 Primers used for the studying disease resistance in Vigna mungo genotypes

\begin{tabular}{|c|c|c|c|}
\hline S. no. & Name & Primer sequence & $\mathrm{Tm}$ \\
\hline 1 & OPN1 & CTCACGTTGG & 20.88 \\
\hline 2 & OPN2 & ACCAGGGGCA & 34.94 \\
\hline 3 & OPN3 & GGTACTCCCC & 22.41 \\
\hline 4 & OPN4 & GACCGACCCA & 29.8 \\
\hline 5 & OPN5 & ACTGAACGCC & 24.88 \\
\hline 6 & OPN6 & GAGACGCACA & 20.34 \\
\hline 7 & OPN7 & CAGCCCAGAG & 25.29 \\
\hline 8 & OPN8 & ACCTCAGCTC & 16.65 \\
\hline 9 & OPN9 & TGCCGGCTTG & 38.73 \\
\hline 10 & OPN10 & ACAACTGGGG & 24.06 \\
\hline 11 & OPN11 & TCGCCGCAAA & 40.01 \\
\hline 12 & OPN12 & CACAGACACC & 11.5 \\
\hline 13 & OPN13 & AGCGTCACTC & 18.1 \\
\hline 14 & OPN14 & TCGTGCGGGT & 36.84 \\
\hline 15 & OPN15 & CAGCGACTGT & 19.87 \\
\hline 16 & OPN17 & CATTGGGGAG & 25.36 \\
\hline 17 & OPQ1 & GGGACGATGG & 29.62 \\
\hline 18 & OPQ2 & TCTGTCGGTC & 18.18 \\
\hline 19 & OPQ3 & GGTCACCTCA & 17.53 \\
\hline 20 & OPQ4 & AGTGCGCTGA & 27.07 \\
\hline 21 & OPQ5 & CCGCGTCTTG & 33.18 \\
\hline 22 & OPQ6 & GAGCGCCTTG & 32.02 \\
\hline 23 & OPQ8 & CTCCAGCGGA & 31.46 \\
\hline 24 & OPQ9 & GGCTAACCGA & 26.67 \\
\hline 25 & OPQ16 & AGTGCAGCCA & 26.54 \\
\hline 26 & OPF1 & ACGGATCCTG & 23.93 \\
\hline 27 & OPF2 & GAGGATCCCT & 20.83 \\
\hline 28 & OPF3 & CCTGATCACC & 17.7 \\
\hline 29 & OPF4 & GGTGATCAGG & 17.7 \\
\hline 30 & OPH 3 & AGACGTCCAC & 16.83 \\
\hline 31 & OPH 6 & ACGCATCGCA & 33.99 \\
\hline 32 & OPH 7 & CTGCATCGTG & 22.22 \\
\hline 33 & OPH 8 & GAAACACCCC & 23.58 \\
\hline 34 & OPH 11 & CTTCCGCAGT & 25.64 \\
\hline 35 & OPH12 & ACGCGCATGT & 32.54 \\
\hline 36 & OPH15 & AATGGCGCAG & 32.75 \\
\hline 37 & OPH18 & GAATCGGCCA & 31.64 \\
\hline 38 & OPJ15 & TGTAGCAGGG & 21.52 \\
\hline
\end{tabular}

focuses on understanding the crux of producing multiple disease resistant crop variety which can replace single disease resistant variety having respectable crop yield.

DNA-based markers are effective and reliable tools for measuring genetic diversity in crop germplasm and studying evolutionary relationship. Molecular genetic techniques using DNA polymorphism is increasingly used to characterize and identify a novel germplasm for uses in 


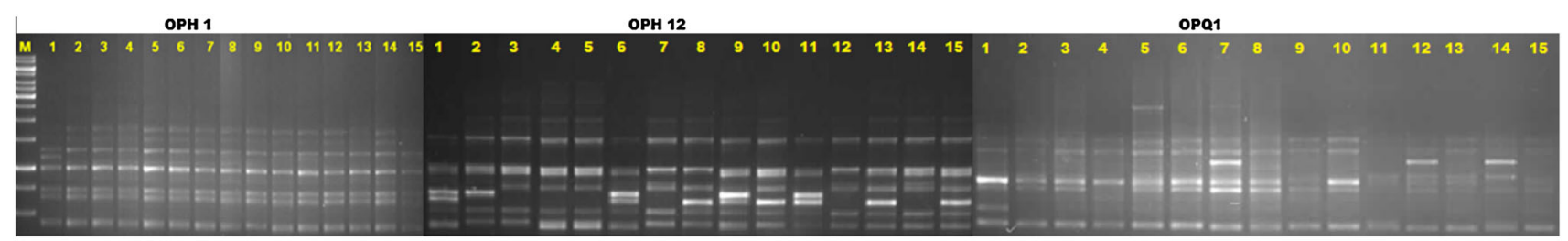

Fig. 1 RAPD amplification pattern of black gram genotypes with primer OPH3, OPH12 and OPQ1. Lane- $M-1 \mathrm{~kb}$ marker, lanes $1-15$ indicate PU31, PU205, PU1075, LBG 623, LBG 645, LBG 685, IC-
1575, IC-20880, IC-59718, IC-61603, IC-61106, IC-73306, IC110790, IC-145202 and IC-164118

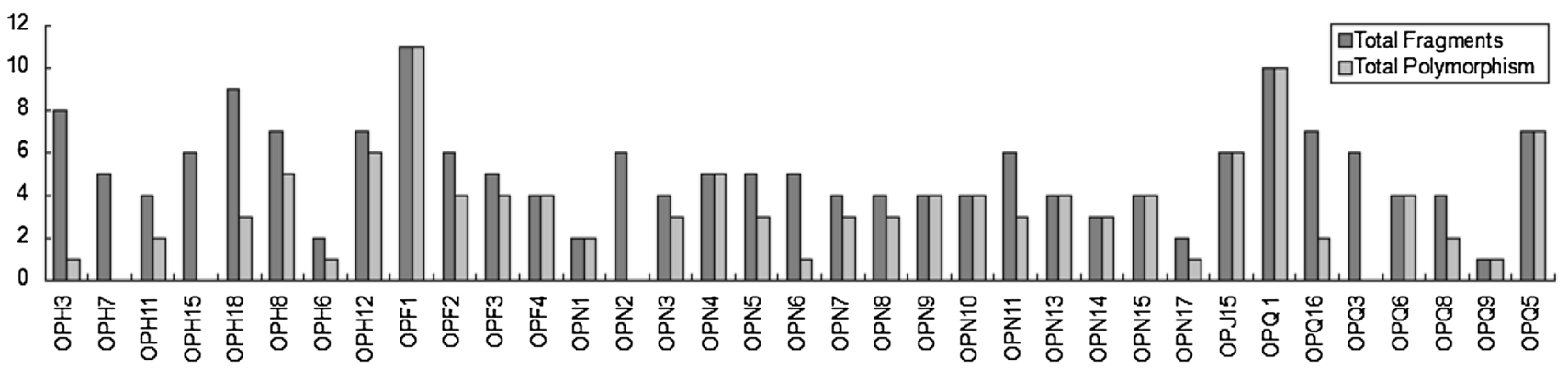

Fig. 2 Bar graph showing various fragments produced by primers and total polymorphisms produced by them

the crop breeding process (Collard and Mackill 2008). Most markers produced polymorphisms, with the exception of OPH3, OPH12 and OPQ1 (Fig. 1) which showed monomorphic bands. Percentage polymorphism was calculated by considering the amount of polymorphism produced per fragment. OPF1, OPF4, OPN1, OPN4, OPN9, OPN10, OPN13, OPN14, OPN15,OPJ15, OPQ1, OPQ6, OPQ9, OPQ5 showed 100\% polymorphism, where OPF1 generated maximum number of fragments (Fig. 2).

After performing SAHN clustering on the binary matrix with subsequent calculation of Jaccard's similarity dendrogram, the major cluster of 15 genotypes was divided into two sub-clusters, i.e., cluster I and cluster II at $64 \%$ of similarity. Cluster I accommodated PU-31, PU-205, PU1075, LBG-623, IC-1575, IC-20880, LBG-645 and LBG685, while cluster II comprised IC-59718, IC-61063, IC61106, IC-73306, IC-110790, IC-145202 and IC-164118. Cluster I was further divided into two sub-clusters, i.e., Cluster Ia and Cluster Ib at $66 \%$ genetic similarity. Cluster Ia included three varieties, namely PU-31, PU-205 and PU1075 displayed $74 \%$ similarity with remaining samples of cluster Ib. Cluster Ib was further divided into two clusters $\mathrm{Ib}_{1}$ and $\mathrm{Ib}_{2}$ at $73 \%$ of similarity. Cluster $\mathrm{Ib}_{1}$ had one MYMV susceptible variety (LBG-623) and two MYMV susceptible accessions, i.e., IC-1575 and IC-20880 and displayed $76 \%$ similarity with remaining samples of cluster $\mathrm{Ib}_{2}$. $\mathrm{Ib}_{2}$ accommodated two MYMV susceptible varieties, i.e., LBG-645 and LBG-685 which displayed 79\% similarity with all the remaining samples in the cluster. Cluster II was further divided into two sub-clusters, i.e., IIa and IIb at $77 \%$ of similarity. The sub-cluster IIa contained one accession, i.e., IC-59718 which displayed 74\% similarity with all remaining samples of cluster $\mathrm{IIb}$ and sub-cluster $\mathrm{IIb}$ was further divided into two clusters $\mathrm{IIb}_{1}$ and $\mathrm{IIb}_{2}$. IIb cluster displayed three accessions, i.e., IC-61063, IC-61106 and IC-73306 displayed $77 \%$ similarity with remaining samples of cluster $\mathrm{IIb} 2$ cluster. Cluster $\mathrm{IIb}_{2}$ showed three accessions IC-110790, IC-145202 and IC-164118 displayed $88 \%$ similarity with all the remaining samples in the cluster (Fig. 3).

Dendrogram analysis revealed that black gram accessions (IC-145202) and (IC-164118) had equal similarities, thus could not be used in hybridization process. Earlier, genetic diversity in black gram was studied using multivariate techniques on the basis of agronomic characters and identified the best genotypes for breeding (Ghafoor et al. 2001). Studies on genetic relationships between wild and cultivated Vigna species were done by cluster analysis and genetic distance determination using RAPD polymorphic markers (Sudha et al. 2014). Our studies clearly showed that the chosen varieties could be used for hybridization process.

This result indicates that there is a presence of great genetic variability among elite genotypes of black gram. The IC-164118 and IC-145202 showed very minimum differences and the maximum difference showed between PU-31 variety and IC-145202 accession at genotypic levels (Fig. 3).

Analysis of the relationship based on 33 RAPD markers revealed genetic diversity among the three resistant varieties and three susceptible varieties along with nine accessions. All the black gram samples were distinguished 
Fig. 3 Dendogram of disease resistant and susceptible varieties, along with nine accessions using Jaccard's similarity coefficient and UPGMA clustering. (MYMV mung bean yellow mosaic virus, $U C L V$ urdbean leaf crinkle virus, $P M$ powdery mildew)

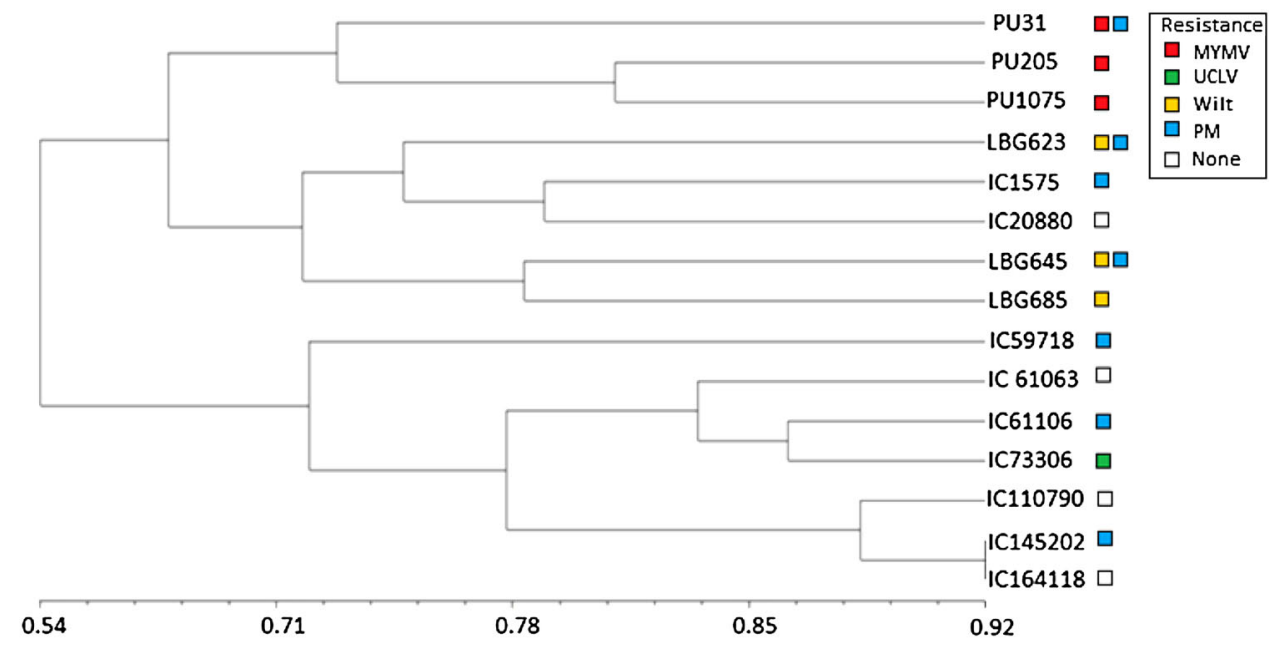

from one another based on these polymorphic bands. A dendrogram was prepared based on identity matrix taking into account the presence (1) or absence (0) of the bands. These coefficients have divided into two major clusters ranged from 0.64 to 0.92 . The similarity coefficient was higher between IC-145202 (PM resistant) and IC-164118 (Disease susceptible) was 0.921 indicated less divergence between them. Lower similarity was observed between PU31 (Resistant to MYMV and PM) and IC-145202 was 0.572 indicating high divergence.

Additionally, one RAPD marker, i.e., OPH-3 showed a resistance specific band in PU-31(MYMV resistant variety) and absent in remaining genotypes (Fig. 1. OPH-3 marker), this marker might be linked to MYMV resistance and can be useful for allele-specific sequence characterized amplicon region primer (SCAR). Although PU201 and PU1075 have phenotypically showed resistance to MYMV, but we did not get the expected band (1300 bp) in PU201 and PU1075, which indicates that there may be another new gene(s) showing resistance to MYMV in PU201 and PU1075. Hence, we suggest PU31 for producing disease resistant crosses in black gram genotypes.

This study could potentially identify diverse genotypes like PU 31(resistant to MYMV and PM) and IC-164118 (susceptible to MYMV and PM) for their use in the breeding program, further PU31 with LBG685 can yield resistance to MYMV, PM and wilt, while PU31 with IC73306 can yield resistance to MYMV, PM and UCLV. RAPD markers are useful in the assessment of black gram diversity, through detection of duplicate samples in germplasm collection, and the selection of a core collection to enhance the efficacy of germplasm management for use in black gram breeding and conservation programs. The genetic diversity obtained in this study might be useful in future strategies for the evolution of desired genotypes.

\section{Conclusion}

Analysis of genetic diversity has aided in producing new varieties of a crop of interest, which are either high yielding or disease resistant. However, it has been traditionally confined to a particular disease and not a set of diseases which affect the crop. Since the advent of manufacture of disease resistant varieties in black gram research has focussed on making high yielding varieties which are also disease resistant. This has lead to multiple strains which have best of both worlds; however, producing a variety which is resistant to multiple diseases has always been a challenge. Our results show that significant divergence in black gram varieties has occured due to genesis of multiple breeding programs across agricultural institutes around the world. Our study has exploited this phenomenon and predicted which crosses are actually resistant to multiple diseases.

We have considered top disease factors which affect the yield of $V$. mungo to establish better crosses and improve crop production. Although we cannot predict a cross which can be resistant to all the four diseases at present, we are currently in the process of hybridizing and analyzing genetic diversity of the crosses and predicting a completely novel disease resistant black gram variety.

Acknowledgements The authors gratefully acknowledge the Agri Biotech Foundation and BCIL (Biotech Consortium India Limited) for providing facilities to carry out the work.

\section{Compliance with ethical standards}

Conflict of interest The authors declare that they have no conflict of interest.

Ethical standard The authors declare that the studies are done in compliance with ethical standards. 
Open Access This article is distributed under the terms of the Creative Commons Attribution 4.0 International License (http:// creativecommons.org/licenses/by/4.0/), which permits unrestricted use, distribution, and reproduction in any medium, provided you give appropriate credit to the original author(s) and the source, provide a link to the Creative Commons license, and indicate if changes were made.

\section{References}

Amanullah M, Hatam M (2000) Yield potential of blackbean (Vigna mungo (L.) Hepper) Germplasm. Pak J Biol Sci 3(10):1571-1573. doi:10.3923/pjbs.2000.1571.1573

Basak J, Kundagrami S, Ghose TK, Pal A (2004) Development of yellow mosaic virus (YMV) resistance linked DNA marker in Vigna mungo from populations segregating for YMV-reaction. Mol Breed 14(4):375-383. doi:10.1007/s11032-004-0238-y

Collard BCY, Mackill DJ (2008) Marker-assisted selection: an approach for precision plant breeding in the twenty-first century. Philos Trans R Soc B Biol Sci 363(1491):557-572. doi:10.1098/ rstb.2007.2170

Datta S, Gangwar S, Kumar S, Gupta S, Rai R, Kaashyap M, Singh P, Chaturvedi SK, Singh BB, Nadarajan N (2012) Genetic diversity in selected Indian mungbean [Vigna radiata (L.) Wilczek] Cultivars using RAPD markers. Am J Plant Sci 03(08):1085-1091. doi:10.4236/ajps.2012.38130

Gautam NK, Kumar K, Prasad M (2016) Leaf crinkle disease in urdbean (Vigna mungo L. Hepper): an overview on causal agent, vector and host. Protoplasma 253(3):729-746. doi:10.1007/ s00709-015-0933-z

Ghafoor A, Sharif A, Ahmad Z, Zahid MA, Rabbani MA (2001) Genetic diversity in blackgram (Vigna mungo L. Hepper). Field Crops Res 69(2):183-190. doi:10.1016/s0378-4290(00)00141-6

Handerson C, Noren SK, Wricha T, Meetei NT, Khanna VK, Pattanayak A, Datt S, Choudhury PR, Kumar M (2014) Assessment of genetic diversity in pea (Pisum sativum L.) using morphological and molecular markers. Indian J Genet Plant Breed (The) 74(2):205. doi:10.5958/0975-6906.2014.00157.6

Haq QMI, Ali A, Malathi VG (2010) Engineering resistance against mungbean yellow mosaic India virus using Antisense RNA. Indian J Virol 21(1):82-85. doi:10.1007/s13337-010-0003-2

Jayasekhar M, Ebenezar EG (2016) Management of powdery mildew of black gram (Vigna mungo) caused by Erysiphe polygoni. Agric Sci Dig Res J. doi:10.18805/asd.v35i1.9317

Karuppanapandian T, Wang HW, Karuppudurai T, Rajendhran J, Kwon M, Jang CS, Kim S, Manoharan K, Kim W (2010)
Efficiency of RAPD and ISSR markers in assessing genetic diversity and relationships in black gram (Vigna mungo L. Hepper) vari. Can J Plant Sci 90(4):443-452. doi:10.4141/ cjps 10014

Kumari N, Thakur SK (2014) Randomly amplified polymorphic DNA-a brief review. Am J Anim Vet Sci 9(1):6-13. doi:10. 3844/ajavsp.2014.6.13

Saghai-Maroof MA, Soliman KM, Jorgensen RA, Allard RW (1984) Ribosomal DNA spacer-length polymorphisms in barley: Mendelian inheritance, chromosomal location, and population dynamics. Proc Natl Acad Sci 81(24):8014-8018. doi:10.1073/ pnas.81.24.8014

Singh PK, Sharma H, Srivastava N, Bhagyawant SS (2014) Analysis of genetic diversity among wild and cultivated chickpea genotypes employing ISSR and RAPD markers. Am J Plant Sci 05(05):676-682. doi:10.4236/ajps.2014.55082

Sivaprakash K, Prashanth S, Mohanty B, Parinda A (2004) Genetic diversity of black gram (Vigna mungo) landraces as evaluated by amplified fragment length polymorphism markers. Curr Sci 86(10):1411-1415

Souframanien J, Gopalakrishna T (2004) A comparative analysis of genetic diversity in blackgram genotypes using RAPD and ISSR markers. Theor Appl Genet 109(8):1687-1693. doi:10.1007/ s00122-004-1797-3

Sudha M, Karthikeyan A, Shobhana VG, Nagarajan P, Raveendran M, Senthil N, Pandiyan M, Angappan K, Balasubramanian P, Rabindran R, Bharathi M (2014) Search for Vigna species conferring resistance to mungbean yellow mosaic virus in mungbean. Plant Genet Res 13(02):162-167. doi:10.1017/ s1479262114000859

Vyas D, Joshi A, Rajamani G, Jain D, Kaur G (2016) Genetic diversity analysis in different genotypes of black gram [Vigna mungo (L.) Hepper] using RAPD marker. Legume Res Int J (OF). doi:10.18805/lr.v0iof.9430

Wani IA, Sogi DS, Gill BS (2013) Physical and cooking characteristics of black gram (Phaseolus mungo L.) cultivars grown in India. Int J Food Sci Technol 48(12):2557-2563. doi:10.1111/ ijfs. 12249

Xu Y, Lu Y, Xie C, Gao S, Wan J, Prasanna BM (2012) Wholegenome strategies for marker-assisted plant breeding. Mol Breed 29(4):833-854. doi:10.1007/s11032-012-9699-6

Yadav K, Yadav SK, Yadav A, Pandey VP, Dwivedi UN (2014) 'Comparative analysis of genetic diversity among cultivated pigeon pea (Cajanus cajan (L) Millsp.) and its wild relatives $(C$. albicans and $C$. lineatus) using randomly amplified polymorphic DNA (RAPD) and inter simple sequence repeat (ISSR). Am J Plant Sci 05(11):1665-1678. doi:10.4236/ajps.2014.511181 